\title{
Um Relato de Experiência da Aplicação de Gamificação e Game Design com Professores
}

\author{
Thiago Reis da Silva ${ }^{1}$ \\ ${ }^{1}$ Instituto Federal de Educação, Ciência e Tecnologia do Maranhão - IFMA \\ Campus São João dos Patos \\ Grupo de Pesquisa em Ambientes Inteligentes, IoT e Sistemas Educacionais - GRAISE \\ thiago.reiseifma.edu.br
}

\begin{abstract}
Resumo. Este artigo apresenta os resultados de uma experiência na disciplina de Informática Educacional com professores do ensino infantil e fundamental da rede pública de ensino do Maranhão, alunos do Plano Nacional de Formação dos Professores da Educação Básica (PARFOR) do curso de Biologia para a utilização de etapas iniciais do Game Design e Gamificação. Os professores demonstraram compreender os conceitos apresentados, além de manterem-se engajados na realização das atividades. As análises sugerem que a Gamificação e o Game Design favorecem a apresentação dos conteúdos $e$ se manifestam como uma possibilidade relevante para o ensino $e$ aprendizagem das disciplinas.
\end{abstract}

Abstract. This article presents the results of an experience in the discipline of Educational Informatics with teachers of elementary and junior high school teaching in Maranhão, students of the National Plan for the Training of Teachers of Basic Education (PARFOR) of the Biology course for the use of Initial stages of Game Design and Gamification. The teachers demonstrated to understand the presented concepts, besides remaining engaged in the accomplishment of the activities. The analyzes suggest that Gamification and Game Design favor the presentation of the contents and are manifested as a relevant possibility for the teaching and learning of the disciplines.

\section{Introdução}

Ao se observar eventos na área de Informática e Educação, pode-se verificar que vários recursos tecnológicos têm sido explorados e aplicados por pesquisadores e educadores para melhorar o sistema educacional. Por exemplo, o uso de jogos na aprendizagem é cada vez mais aplicado devido às suas características motivacionais e desafiadoras aos jogadores [Silva et. al. 2014].

O poder motivacional dos jogos tem sido explorado também em contextos da vida real, através da técnica denominada Gamificação (Gamification) [Kapp 2012], que consiste em aplicar elementos de jogos a contextos reais, de forma a motivar pessoas a adotarem novos comportamentos, por exemplo, aprender um novo conteúdo. A aplicação do Game Design também tem sido utilizada por professores da educação básica, como forma de enriquecer o processo educacional e como recurso para sua formação [Araújo, Silva e Aranha 2016]. 
Nesse contexto, o uso de elementos de jogos na educação é uma das possibilidades para explorar o conhecimento, possibilitando aos alunos aprenderem enquanto brincam. Diante desses aspectos, a Gamificação e o Game Design têm despertado o interesse da comunidade científica e tornaram-se objetos de pesquisa, como instrumentos de aprendizagem em diversos áreas, inclusive na Formação de Professores [Araújo, Silva e Aranha 2016] [Sant'Anna e Neves 2011].

Sendo assim, apresentamos neste artigo um relato de experiência na formação de professores do ensino infantil e fundamental da rede pública de ensino do Maranhão (MA), da cidade de São Raimundo das Mangabeiras (MA), na disciplina de Informática Educacional do curso de Licenciatura em Biologia, realizada no contexto do programa PARFOR $^{1}$, que teve como objetivo introduzir noções de Tecnologia de Informação e Comunicação (TIC) para os professores. O objetivo do PARFOR é fomentar a oferta de educação superior, gratuita e de qualidade, para professores em exercício na rede pública de educação básica ${ }^{1}$. A disciplina teve carga horária de 60 horas e foi ministrada em quatro fins de semana. Para o conteúdo de Gamificação e Game Design foram realizadas oficinas para a aplicação dessas técnicas na educação. Nesse sentido, além de descrever a realização da disciplina e seus resultados, o estudo avaliou o feedback dos participantes no que diz respeito, entre outras coisas, ao nível de satisfação com as atividades, pontos fortes e fracos das técnicas e a contribuição para a formação dos mesmos.

Portanto, este trabalho está organizado na seguinte forma: na Seção 2 reportamos sobre Formação dos Professores com as TICs e apresentamos alguns estudos relacionados, a Seção 3 apresenta a metodologia utilizada nas oficinas, a Seção 4 apresenta os resultados das oficinas, a Seção 5 detalha a avaliação dos participantes e, a Seção 6 apresenta as Lições Aprendidas no estudo e, por fim, a seção 7 detalha as Conclusões Finais e apresenta as Perspectivas de Trabalhos Futuros.

\section{Formação de Professores}

Estudos têm demonstrado que a utilização das TICs, como ferramenta para auxiliar os professores, traz uma contribuição para a prática escolar em todos níveis de ensino [Procópio 2011]. Essa utilização apresenta possibilidades que poderão ser realizadas como auxílio nas atividades pedagógicas dos mesmos. Porém, o debate sobre a formação de professores, bem como as possibilidades e desafios dessa formação é outro ponto que vem sendo pesquisado. Bittar (2011) debate a formação de professores de forma que esses passem a integrar a tecnologia em suas aulas e não apenas inseri-las como um recurso ilustrativo e motivador. Neste aspecto, é necessária uma formação continuada para atualizar esses profissionais.

A formação de professores por meio das tecnologias digitais visa o desenvolvimento profissional e também proporciona qualificação acadêmica [Procópio 2011]. Segundo Gatti (2016) projetos de formação de professores realizados com apoio das TICs vêm respondendo, com uma certa qualidade, principalmente, pela elaboração de materiais de apoio à formação para a docência e pelos cuidados tomados na produção do material. Sendo assim, considerando os aspectos citados foi elaborada uma proposta

\footnotetext{
${ }^{1}$ http://www.capes.gov.br/educacao-basica/parfor
} 
VI Congresso Brasileiro de Informática na Educação (CBIE 2017)

Anais do XXIII Workshop de Informática na Escola (WIE 2017)

de formação de professores com o uso da Gamificação e Game Design para auxiliar no ambiente escolar.

Gamificação significa aplicar técnicas e elementos utilizados no desenvolvimento dos jogos digitais, como estética e mecânica, em outros contextos, com a finalidade de motivar e auxiliar na solução de problemas e promover a aprendizagem [Kapp 2012]. Para Seixas et. al., (2014) a inserção da Gamificação no contexto educacional vem acontecendo gradualmente com a finalidade de tornar esses conteúdos mais interessantes e atrativos. Já o Game Design é o ato de decidir o que um jogo digital deve ser, é o processo de projetar, elaborar regras, criar mecânicas, definir enredos, ou seja, especificar claramente as características de um jogo digital [Schell 2011].

Alguns estudos sobre a formação de professores com o uso da Gamificação, Game Design e outros recursos tecnológicos já foram reportados. Silva et. al., (2014) apresentam os resultados de uma oficina de Gamificação com 181 professores do ensino público do Rio Grande do Norte (RN). Os resultados reportam que as oficinas foram bem avaliadas e que os professores demonstram disposição em utilizar este conceito no ambiente escolar. Araújo, Silva e Aranha (2016) relatam uma experiência de formação de 229 professores do ensino básico da rede pública do estado do RN para a utilização de etapas iniciais do Game Design. Em contrapartida, Santana e Neves (2011) apresentam os resultados de um projeto para formação de professores para utilizar a linguagem de programação Scracth para incentivar o pensamento computacional. Este estudo desenvolveu um processo similar ao apresentado em Silva et. al., (2014) e Araújo, Silva e Aranha (2016), no entanto, este trabalho tem como diferencial o fato de apresentar os resultados da prática feita pelos professores nas escolas em que atuam.

\section{Metodologia}

Este trabalho trata-se de uma pesquisa aplicada, baseado nos estudos de Silva et. al., (2014). Para a coleta de dados foi desenvolvido um questionário de múltipla escolha. A elaboração do questionário foi desenvolvida através de pesquisas, onde abordava a utilização da Gamificação e Game Design como ferramenta auxiliar para formação dos professores, dando-lhe um suporte a mais e visando fortalecer o processo de construção do seu conhecimento. Sendo assim, a metodologia utilizada para o estudo adotou as seguintes fases detalhadas na Tabela 1 .

Tabela 1: Planejamento das oficinas.

\begin{tabular}{|l|l|}
\hline \multicolumn{1}{|c|}{ Fase } & \multicolumn{1}{c|}{ Descrição } \\
\hline $\begin{array}{l}\text { Levantamento } \\
\text { bibliográfico }\end{array}$ & $\begin{array}{l}\text { Realizou-se um levantamento bibliográfico, contemplando o uso da Gamificação e } \\
\text { Game Design no ambiente escolar e na formação dos professores. }\end{array}$ \\
\hline $\begin{array}{l}\text { Planejamento das } \\
\text { oficinas }\end{array}$ & $\begin{array}{l}\text { Preparação dos recursos didáticos a serem utilizados nas oficinas e as atividades a } \\
\text { serem realizadas nas escolas, considerando: (i) os temas Gamificação e Game } \\
\text { Design; e (ii) desconhecimento do assunto por parte dos professores. }\end{array}$ \\
\hline $\begin{array}{l}\text { Aplicação das } \\
\text { oficinas }\end{array}$ & $\begin{array}{l}\text { Durante as oficinas os participantes foram instruídos sobre conceitos e abordagens } \\
\text { de Gamificação e Game Design. Em seguida, foram disponibilizados, papeis, } \\
\text { pinceis, lápis e tesoura, para que proponham um conceito de jogo utilizando o } \\
\text { processo de Game Design como resposta a um problema apresentado pelo } \\
\text { professor e que apresentasse uma solução com o uso da Gamificação dos } \\
\text { problemas cotidiano escolar. }\end{array}$ \\
\hline $\begin{array}{l}\text { Seminário de } \\
\text { resultados }\end{array}$ & $\begin{array}{l}\text { Os participantes, organizados em grupos, após aplicarem o processo de } \\
\text { Gamificação e Game Design nas escolas, apresentaram os resultados obtidos em }\end{array}$ \\
\hline
\end{tabular}


VI Congresso Brasileiro de Informática na Educação (CBIE 2017)

Anais do XXIII Workshop de Informática na Escola (WIE 2017)

\begin{tabular}{|l|l|}
\hline & um seminário. \\
\hline $\begin{array}{l}\text { Aplicação do } \\
\text { Questionário }\end{array}$ & $\begin{array}{l}\text { Ao final da disciplina foram aplicados questionários de avaliação com os } \\
\text { participantes. Os resultados obtidos foram analisados. }\end{array}$ \\
\hline
\end{tabular}

As oficinas foram organizadas para que as atividades fossem executadas em três momentos: (i) teoria; (ii) prática e; (iii) seminário. No primeiro momento, foram apresentadas as concepções e conceitos fundamentais da área de jogos, especialmente de jogos digitais e dos processos do Game Design, bem como a sua relação com práticas inovadoras aplicadas à educação com o uso da Gamificação. Na segunda etapa, os participantes, organizados em grupos, aplicaram a oficina de Game Design e Gamificação nas escolas em que atuavam. Na terceira e última etapa, os grupos apresentaram os resultados alcançados em um seminário. As oficinas seguiram a seguinte dinâmica detalhadas na Tabela 2.

\section{Tabela 2: Dinâmica das oficinas.}

\begin{tabular}{|c|c|}
\hline \multirow[b]{2}{*}{ Game Design } & \\
\hline & Gamificação \\
\hline $\begin{array}{l}\text { Introdução aos jogos digitais e ao seu } \\
\text { processo de criação: foi apresentado o } \\
\text { propósito da oficina e os conceitos } \\
\text { relacionados a jogos digitais e seu processo de } \\
\text { desenvolvimento com atenção ao Game } \\
\text { Design; } \\
\text { Orientações para a definição de um } \\
\text { conceito de jogo utilizando os processos do } \\
\text { Game Design: apresentou-se um passo a } \\
\text { passo do processo de desenvolvimento de } \\
\text { jogo dentro do Game Design. O passo a passo } \\
\text { aplicado foi: (i) Formulação do problema; (ii) } \\
\text { Compreensão do problema; (iii) Sessão de } \\
\text { Brainstorming para definição de soluções; } \\
\text { (iv) Descrição da melhor solução; (v) Refino } \\
\text { da melhor solução; (vi) Elaboração do GDD } \\
\text { através do Página-Única; } \\
\text { Prática para os professores: a partir das } \\
\text { orientações da fase anterior, foi solicitado aos } \\
\text { participantes que criassem um conceito de } \\
\text { jogo a partir da compreensão de um problema } \\
\text { e em seguida apresentassem a sua solução em } \\
\text { um seminário; e } \\
\text { Avaliação dos resultados: ao final das } \\
\text { oficinas foi distribuído um questionário entre } \\
\text { os participantes, com o objetivo de verificar } \\
\text { os resultados e as opiniões dos participantes } \\
\text { sobre as oficinas. }\end{array}$ & $\begin{array}{l}\text { Introdução a Gamificação: foi apresentado o propósito } \\
\text { da oficina e os conceitos relacionados à Gamificação, } \\
\text { descrevendo algumas linhas gerais de sua aplicação. } \\
\text { Nesta fase foram também apresentados vídeos e } \\
\text { reportagens motivadoras, relacionados ao funcionamento } \\
\text { e vantagens da utilização da Gamificação no ambiente } \\
\text { escolar; } \\
\text { Exemplo da aplicação da Gamificação no contexto } \\
\text { escolar: foi apresentando um passo a passo da aplicação } \\
\text { da Gamificação no contexto escolar, a serem repetidos } \\
\text { pelos professores na fase da prática, identificando: (i) o } \\
\text { contexto do trabalho; (ii) problemas/comportamentos } \\
\text { indesejados, e suas causas; (iii) mudanças de } \\
\text { comportamento desejadas; (iv) jogadores envolvidos; (v) } \\
\text { o que motiva esses jogadores; (vi) como fazer uso dessas } \\
\text { motivações para que os jogadores mudem seus } \\
\text { comportamentos; (vii) como elementos de diversão } \\
\text { podem ser inseridos; e (viii) como manter o ciclo de } \\
\text { engajamento dos jogadores com o passar do tempo (e da } \\
\text { novidade); } \\
\text { Prática para os professores: de acordo com os passos } \\
\text { identificados na atividade anterior, foi solicitado aos } \\
\text { professores que identificassem um problema, e que } \\
\text { trabalhassem em possíveis soluções gamificadas para } \\
\text { amenizar ou eliminar o problema, seguindo os passos } \\
\text { apresentados na etapa anterior; e } \\
\text { Apresentações de propostas: neste momento final da } \\
\text { oficina, os professores compartilham o problema alvo } \\
\text { identificado e a proposta de Gamificação trabalhada pelo } \\
\text { grupo. }\end{array}$ \\
\hline
\end{tabular}

\section{Resultados}

As oficinas possibilitaram aos participantes conhecerem noções básicas sobre Game Design e o seu processo de criação, Gamificação, além de refletirem sobre a viabilidade da aplicação dessas técnicas nas escolas e de como compartilhar o conhecimento para outros professores. 
VI Congresso Brasileiro de Informática na Educação (CBIE 2017)

Anais do XXIII Workshop de Informática na Escola (WIE 2017)

\subsection{Perfil dos professores}

O estudo foi realizado com a participação de 9 professores (ver Tabela 3). Desses, 3 possuíam formação superior completa (P1, P6 e P7), 3 possuíam o curso de Magistério (P2, P5 e P9) e 3 continham Ensino Médio completo (P3, P4 e P8). Em relação ao sexo: $10 \%$ são do sexo masculino, e $90 \%$ do sexo feminino. Os professores tinham entre 22 a 50 anos de idade, sendo a média de 33 anos. Para realização das atividades propostas foram divididos professores em dois grupos. Um grupo com 5 professores aplicou a oficina de Gamificação e o outro grupo com 4 professores aplicou a uma oficina de Game Design.

Tabela 3: Perfil dos Professores.

\begin{tabular}{|c|c|c|c|c|}
\hline Professores & Idade & Formação & Atuação & $\begin{array}{c}\text { Tempo de } \\
\text { Serviço }\end{array}$ \\
\hline P1 & 29 & Pedagogia & Ensino Fundamental - a a 5 $^{\text {a }}$ ano & 6 anos \\
\hline P2 & 36 & Magistério & Ensino Fundamental - $1^{\text {a }}$ ano & 6 anos \\
\hline P3 & 28 & Ensino Médio & Ensino Fundamental - EJA & 5 anos \\
\hline P4 & 22 & Ensino Médio & Ensino Infantil - Pré escola & 4 anos \\
\hline P5 & 28 & Magistério & Ensino Infantil - I e II & 8 anos \\
\hline P6 & 43 & Ciências Biológicas & Ensino Infantil - Pré escola & 11 anos \\
\hline P7 & 30 & Pedagogia & Ensino Infantil - Pré escola & 6 anos \\
\hline P8 & 33 & Ensino Médio & Ensino Infantil - Pré escola & 5 anos \\
\hline P9 & 50 & Magistério & Ensino Fundamental - ${ }^{\text {a }}$ ano & 26 anos \\
\hline
\end{tabular}

\subsection{Game Design - resultado encontrado}

Primeiramente um exemplo foi apresentado para que os participantes tomassem como base. O problema compreendia criar uma ideia de jogo não digital que trabalhasse habilidades dos componentes curriculares, como Português ou Matemática. Na Tabela 4, é apresentada a solução proposta pelo grupo que executou a oficina na escola estadual Unidade Integrada Dom Rino Carlesi, na Cidade de São Raimundo das Mangabeiras MA.

Tabela 4: Ideia do Jogo.

\section{Título: Campões da Matemática}

Público-alvo: Estudantes da educação fundamental.

Área: Matemática: operações básicas (somar, subtração, multiplicação e divisão).

Jogo: a ideia do jogo é fazer perguntas aos alunos da Tabuada. Para cada número da Tabuada existe um fio ligado a uma lâmpada, quando o aluno responde a operação certa, a lâmpada é acendida, caso contrário, ela não acende. Cada aluno tem direito a apenas uma pergunta, caso ele acerte a pergunta, continua no jogo, caso contrário perde a vez.

Objetivo: Ganha o aluno que acerta a maior quantidade de respostas.

Dessa ideia de jogo surgiu a proposta de criar uma gincana e um jogo não digital chamado "Calculada Inteligente" (ver Figura 1a). Essa calculadora foi produzida com papel e cartolina e o jogo funcionava da seguinte forma: o aluno teria que responder corretamente uma operação matemática (Soma, Subtração, Multiplicação ou Divisão), caso a resposta fosse correta, era acendida uma lâmpada, caso contrário a lâmpada não acendia. Por exemplo, se for perguntado ao aluno: Quanto é 3 x 5? A resposta correta será 15 , nesse caso a lâmpada da calculadora acendia, caso contrário o aluno perdia a vez. Essa sequência lógica foi executada até todos os alunos participarem. Ao final foram disponibilizadas medalhas para os alunos que tiveram os melhores resultados na gincana. Nessa oficina participaram uma turma com 25 alunos. 
O modo como os professores avaliaram o problema exemplificado e o jeito criativo como pensaram nas soluções demonstrou que a etapa de definição de conceito de jogo foi bem executada e o resultado aplicado na escola foi significante com o engajamento tanto dos alunos como dos demais professores. Durante as atividades, percebeu-se um envolvimento, descontração e liberdade para criar novas ideias. $\mathrm{O}$ envolvimento de todos também foi observado, mesmo daqueles mais tímidos. Isso foi perceptível através das fotos e vídeos apresentados durante o seminário.

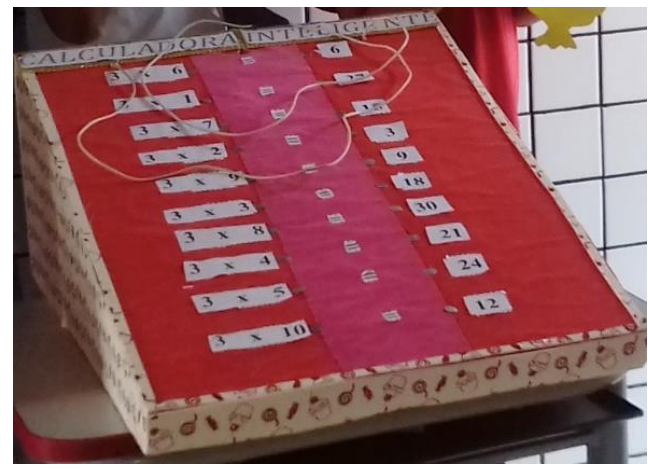

Figura 1: Ideia da Calculadora Inteligente.

Os professores conseguiram compreender o propósito da oficina, aplicando de forma correta os passos indicados para pensarem no problema e em como solucioná-lo utilizando os processos do Game Design, com vistas a transformar a proposta em um jogo não digital. Foram capazes de criar propostas de soluções viáveis com as novas técnicas aprendidas, que são possíveis de implantação nas escolas onde trabalham.

\subsection{Gamificação - resultado encontrado}

Para demonstrar o resultado desenvolvido na Escola Municipal a Cirandinha, Localizada na Cidade de Simbaíba - MA, é apresentada na Tabela 5 um resumo de um problema identificado pelos professores, para o qual foi apresentado uma solução Gamificada. Nessa oficina participaram 20 alunos.

Tabela 5: Problema discutido e solução de Gamificação apresentada. Título: Campões da Matemática

- Contexto: Escolas de educação infantil e fundamental;

1. Problemas/comportamentos indesejados e suas causas:

a) Problema: falta de interesse;

b) Comportamentos indesejados: desmotivação e falta de atenção;

c) Causa: devido aos livros que estão disponíveis na escola serem de leitura muito extensa e sem imagens para eles interpretarem;

2. Mudança de comportamento desejado: criar o desejo e hábito da leitura nas crianças para que assim elas venham futuramente a incentivar outros a gostar de leitura;

3. Jogadores: alunos da educação infantil;

4. O que motiva os jogadores: incentivo dos pais e professores e premiações sugerida por eles;

5. Como motivar os jogadores para mudarem seus comportamentos: criar rodas de leitura e ouvir os alunos a contar suas próprias histórias;

6. Como os jogadores irão se divertir: aprendendo a ter uma leitura visual em completa interação com os colegas, desenvolvendo assim o desejo e o interesse pela leitura;

7. Como manter o ciclo de engajamento: mudança na sala de leitura, criando atrativos como som ambiente, tapetes, almofadas, imagens e jogos educativos.

Diante dos resultados observados, verificamos que os professores conseguiram entender a ideia da Gamificação, aplicando de forma correta os passos indicados para 
pensarem em problemas e em como resolvê-los. Eles de fato foram capazes de criar propostas de soluções viáveis de serem implantadas nas escolas onde trabalham de forma satisfatória.

Uma análise realizada pelos professores destaca que a Gamificação pode ser aplicada para a melhoria do processo de ensino e aprendizagem. Eles destacam que através de uma roda de leitura, por exemplo, pode-se trabalhar vários contextos de forma mais dinâmica e divertida sem tornar as aulas cansativas e maçantes, como é destacado pelo Professor (P7): "A gamificação deveria ser usada com bastante frequência na sala de aula pois, é umas das formas de ensinar mais relativas que se pode concluir, com essa razão já se poderia pensar em livros que apresentasse a gamificação dentro do conteúdo para ser ensinado dentro da sala de aula".

\section{Avaliação}

$\mathrm{Na}$ pesquisa realizada participaram 9 professores da rede pública de ensino do Maranhão. Como já mencionado, o questionário aplicado ao final das oficinas foi dividido em três partes para melhor organizar os dados: avaliação inicial, com questões iniciais sobre conhecimento anterior a realização das oficinas; avaliação da satisfação dos participantes com o conhecimento adquirido, contribuição para sua formação e a avaliação dos pontos fortes e fracos, que serão apresentadas nas subseções a seguir.

Optou-se por realizar esta avaliação de forma quantitativa e qualitativa. Para a avaliação quantitativa fizemos uso da Escala de Likert, que em conformidade com Santos et al., (2014) permite mostrar qual o grau de concordância e/ou discordância do usuário em relação a um determinado objeto e/ou conteúdo.

\subsection{Avaliação inicial}

Quando questionados sobre o nível de conhecimento sobre Game Design e Gamificação, todos os participantes reportaram que não tinham conhecimento sobre o tema anterior à realização da oficina, além disso, quando questionados sobre a estrutura das escolas para a aplicação das oficinas, $78 \%$ responderam que a escola possui estrutura para a aplicação da atividade de Game Design, enquanto outros 22\% relataram a falta de estrutura, por exemplo, laboratórios de computadores defasados e inexistentes. Entretanto, a oficina de Game Design pode ser utilizada em sala de aula convencional, sem o uso de computadores. No entanto, para a atividade de Gamificação, $100 \%$ dos professores reportaram que as escolas têm estrutura para a aplicação das atividades.

\subsection{Avaliação da satisfação e contribuição para a formação}

Em relação ao nível de satisfação dos participantes com as atividades Gamificadas, observou-se que a maioria ficou satisfeita com a sua realização: $56 \%$ dos participantes relataram estarem satisfeitos e $44 \%$ muito satisfeito. Não foram destacados pontos como pouco satisfeito e não satisfeito, demonstrando que o resultado da oficina foi satisfatório para os participantes. Com relação ao nível de contribuição para formação dos participantes: $60 \%$ dos participantes relataram que contribuiu muito para sua formação, $30 \%$ que contribuiu e apenas $10 \%$ relataram que foi pouca a contribuição para sua formação. Nenhum participante relatou que a atividade não contribuiu para a sua formação, o que demonstra que a oficina mudou algo em relação ao conhecimento sobre Gamificação. 
Com relação a oficina de Game Design, sobre o nível de satisfação, os participantes reportaram: $56 \%$ muito satisfeito e $44 \%$ satisfeito. Com relação ao nível de contribuição para sua formação, 44\% reportaram muita contribuição e 56\% que contribuiu.

Mediante as respostas dos participantes, melhoramos o nível de conhecimento dos professores e contribuímos para sua formação apresentando um novo conteúdo que pode auxiliar em suas práticas pedagógicas e ainda destacamos que há motivação para a adoção das práticas nas escolas.

\subsection{Avaliação dos pontos fortes e fracos}

Foram direcionadas duas questões dissertativas para que os participantes expressassem sua opinião sobre os pontos fortes e fracos. Algumas respostas foram análogas no sentido do que almejavam dizer, e por esse motivo foram agrupadas. A seguir são relacionados os grupos de respostas que expressam o mesmo sentido da maioria das respostas dos participantes para os pontos fortes e fracos observados durante as oficinas.

Para a oficina de Gamificação os participantes reportaram como pontos positivos: (i) estimular o raciocínio da aluno; (ii) ajuda a motivar os educandos, a prestarem atenção no conteúdo aplicado e permite, um aprendizado melhor; (iii) ensinar aos alunos e fazer com que eles se tornem, mais desenvolvidos; (iv) envolvimento do professor com os alunos nas atividades; (v) aumenta o interesse e o entusiasmo para resolver e aprender o conteúdo; e (vi) ensinar aos alunos serem competitivos e a trabalhar em equipe. Com relação aos pontos falhos, os mesmos reportam: (i) falta de estrutura na escola; (ii) falta iniciativa por parte do corpo docente e a dificuldade de manuseio do computador; e (iii) pouco tempo das oficinas.

No entanto, para a oficina de Game Design, os pontos positivos apontados foram: (i) muito positivo para ambas partes, tanto para o professor como para os educandos, uma vez que os alunos, se empenham em se sair bem para ter bons resultados e assim o professor ver qual o nível de aprendizado de cada um; (ii) excelente envolvimento escolar; (iii) excelente para o ensino na escola; (iv) manuseio do jogo e a expectativa da vitória no final e tornar os alunos mais informados e competitivos. Com relação aos pontos negativos, destacamos: os educandos podem viciar em estudar somente para ser os melhores, naquele momento e ser premiado e não para aprender para toda uma vida e que muitas vezes a criança tem o interesse só em ganhar e quando perde torna-se agressivo.

Como podemos relatar, ficou evidente os resultados satisfatórios da aplicação dessas atividades no ambiente escolar. No que tange às sugestões, os participantes, em sua maioria, sugerem uma formação para uso das tecnologias para os professores do ensino básico. O Professor (P5) respondeu assim: "Minha sugestão é que todo o corpo docente e discente tenha conhecimento desses recursos, uma vez que, ainda falta muito falta de informação por parte de alguns". E o Professor (P3) destacou: "Que todos os professores de utilizem desse riquíssimo recurso para estimular a aprendizagem de seus alunos". Esses apontamentos indicados pelos professores reforçam a necessidade de formação dos docentes da educação básica para a utilização das novas tecnologias. 
VI Congresso Brasileiro de Informática na Educação (CBIE 2017)

Anais do XXIII Workshop de Informática na Escola (WIE 2017)

\section{Lições Aprendidas}

A formação de professores da educação básica brasileira carrega consigo vários desafios. Primeiramente, os professores não têm formação complementar sobre tecnologias digitais, o que pode dificultar a realização de trabalhos que versem sobre a temática e a inserção das tecnologias digitais nas escolas. Nesta perspectiva, as experiências realizadas, como a detalhada neste estudo revelam a importância de manter uma formação continuada dos professores da educação básica que possibilite a efetivação de ações para o desenvolvimento de habilidades tão necessárias na sociedade digital. A interdisciplinaridade das oficinas realizadas apresenta-se como uma alternativa para a formação dos professores com as novas tecnologias, possibilitando o desenvolvimento de atividades que trabalhem conceitos de outras disciplinas atrelados a momentos lúdicos com a utilização dos princípios da Gamificação e Game Design.

Nas oficinas os professores se submergiram nas atividades de aprendizagem envolvendo conhecimento e diversão relacionada ao desenvolvimento do raciocínio necessário para o desenvolvimento das atividades, por exemplo, criação dos jogos não digitais, que foram construindo com lápis, cartolina, pinceis e a criatividade.

Outro ponto notório foi o envolvimento dos demais profissionais das escolas. Isso demonstra que o estudo realizado motiva a importância da participação dos professores em atividades que objetivem a sua qualificação profissional, já que tais profissionais poderão replicar essas atividades em outras disciplinas e em outras escolas, podendo incentivar o desenvolvimento de ações com tal objetivo.

A experiência vivenciada pelos professores aponta ainda para a importância de estabelecer uma relação lúdica com os alunos, inserindo a ludicidade no processo de aprendizagem. Nesse contexto, atividades lúdicas apresentam-se como alternativa, podendo atrair mais a atenção dos alunos e engajá-los em tarefas de aprendizagem. Além disso, os professores poderão produzir outras oficinas que possibilitem a formação de outros professores.

Uma forma encontrada de demonstrar para os professores como é importante a utilização de métodos alternativos e auxiliares se deu com a utilização das oficinas, uma aplicação que a princípio pode parecer complexa, mas que se mostrou eficiente, pois chamou a atenção dos mesmos. A grande relevância que foi reportada das oficinas foi com relação a facilidade que elas têm em prender a atenção dos alunos e proporcionar com isso um melhor processo de aprendizagem. Em relato, os professores destacaram a possibilidade de as atividades desenvolverem nos estudantes habilidades e competências como raciocínio lógico e trabalho em equipe, o que contribui no desempenho escolar.

\section{Considerações Finais}

O relato presente neste estudo apresentou uma experiência na disciplina de Informática Educacional com alunos do PARFOR, com uso e aplicação das técnicas de Game Design e Gamificação.

O trabalho apresentou resultados que apontam para uma indicação de melhoria do uso das TICs associadas à aprendizagem. Nosso intuito foi apresentar, discutir e exemplificar a aplicabilidade da Gamificação e Game Design nas práticas pedagógicas dos professores. A investigação mostrou que o uso das referidas técnicas teve efeitos 
VI Congresso Brasileiro de Informática na Educação (CBIE 2017)

Anais do XXIII Workshop de Informática na Escola (WIE 2017)

positivos no engajamento dos alunos e dos demais professores das escolas durante a oficina realizada.

Uma contribuição que destacamos é a constatação da relevância e benefícios resultantes da aplicação de Game Design e Gamificação como estratégia no engajamento durante as atividades, visto que essa dinâmica abre possibilidades proporcionando aos professores e, também, aos alunos uma a melhoria do processo de ensino e aprendizagem.

As dificuldades observadas na realização das atividades reforçam o diagnóstico de que os professores ainda não se apropriaram das TICs em geral. Esses dados reforçam a necessidade de mais ações de inserção das TICs em atividades contextualizadas e práticas nas escolas, que levam os professores ao uso desses recursos cada vez mais útil na era do conhecimento digital. Como perspectivas de trabalhos futuros, ampliar esse estudo a outros professores da região e qualificar os mesmos para utilização desses recursos na educação.

\section{Referencias}

Araújo, G. G.; Silva, T. R.; Aranha, E. H. S. (2016) “A Construção de Jogos Digitais na Escola: um Relato de Experiência na Formação de Professores”. In: Workshop de Informática na Escola - WIE, p.161-170, Uberlândia - MG.

Bittar, M. (2011) "A abordagem instrumental para o estudo da integração da tecnologia na prática pedagógica do professor de matemática". In: Educar em Revista: Editora UFPR, Curitiba, Brasil, n.1, p. 157-171.

Gatti, B. A. (2016) "Formação de professores: condições e problemas atuais". In: Revista Internacional de Formação de Professores - RIPF, v.1, n.2, p.162-170.

Kapp, K. (2012) “The Gamification of Learning and Instruction: Game-based Methods and Strategies for Training and Education”. Pfeiffer, 2012.

Procópio, E. R. (2011) "Formação de professores e tecnologias: implicações da educação a distância na prática docente". (Dissertação) Universidade Federal de Juiz de Fora, 139p.

Sant'Anna, H. C.; Neves, V. B. (2012) "Scratch Day UFES: oficina itinerante de introdução a programação para professores". In: IV Simpósio Hipertexto e Tecnologia na Educação, Recife - PE.

Schell, J. (2008) "The Art of Game design: A Book of Lenses”. Burlington: Elsevier.

Silva, T. R.; Araújo, G. G.; Fernandes, J. V. O.; Aranha, E. H. S. (2014) "Oficinas de Gamificação: um relato de experiência com professores do ensino básico”. In: Congresso Internacional de Informática Educativa - TISE, p.678-683.

Seixas, L. R.; Gomes, A. S.; Melo Filho, I. J.; Rodrigues, R. L. (2014) "Gamificação como Estratégia no Engajamento de Estudantes do Ensino Fundamental”. In: XXV Simpósio Brasileiro de Informática na Educação - SBIE. Dourados - MS.

Santos, W. O.; da Silva, A. P.; Silva Junior, C. G. (2014) "Conquistando com o Resto: Virtualização de um Jogo para o Ensino de Matemática”. In: Simpósio Brasileiro de Informática na Educação - SBIE. p. 317-321. 